\title{
A INTERDISCIPLINARIDADE COMO PROPOSTA PARA O ENSINO DE LÓGICA DE PROGRAMAÇÃO NO ENSINO FUNDAMENTAL II
}

\section{INTERDISCIPLINARITY AS A PROPOSAL FOR TEACHING LOGIC PROGRAMMING IN ELEMENTARY SCHOOL II}

\author{
Diego Ricardo Krohl* \\ ORCID: https://orcid.org/0000-0002-0336-2889 \\ Taynara Cerigueli Dutra** \\ ORCID: https://orcid.org/0000-0002-4744-566X \\ Camilla Pozer de Matos*** \\ ORCID: https://orcid.org/0000-0003-1379-4121
}

\section{Resumo}

O presente estudo apresenta um levantamento acerca da interdisciplinaridade, objetivando o refinamento de seu uso, em um projeto de extensão de ensino de lógica de programação para turmas do Ensino Fundamental II, realizado em três escolas públicas catarinenses. Nesse projeto, docentes e estudantes de Ciência da Computação, do Instituto Federal Catarinense, utilizam a ferramenta VisuAlg para atividades de programação que abordam temas cotidianos e escolares. Desse modo, por intermédio da aplicação de um questionário aos docentes das escolas participantes, buscou-se conhecer o contexto escolar e as possibilidades interdisciplinares. Os resultados do levantamento demonstram uma equipe docente experiente e com preceitos para trabalhos conjuntos, com perspectivas a melhorias no processo de ensino-aprendizagem significativo dos estudantes. A primeira turma do projeto apresentou evolução de cerca de $10 \%$ em sua capacidade de resolução de questões lógicas. Com o incremento na parceria dos docentes de modo interdisciplinar, espera-se otimizar esses ganhos.

Palavras-chave: Interdisciplinaridade; Lógica de programação; Ensino fundamental II.

\begin{abstract}
This study presents a survey about interdisciplinarity, aiming at the refinement of its use, in an extension project to teach logic programming in Elementary School II, carried out in three public schools in Santa Catarina. The project gathers computer science teachers and students of the Catarinense Federal Institute, who use the tool VisuAlg to develop activities that approach both daily and school subjects. In this way, through the application of a questionnaire to the teachers of the participating schools, we sought to know the school context and its interdisciplinary possibilities. The results of the survey demonstrate an experienced teaching team with precepts of joint work, with prospects of improvements in the students' meaningful teaching-learning process. The first group that took part in the project presented an evolution of about $10 \%$ in their capacity to solve logical issues, and with the increase in the teachers' partnership in an interdisciplinary way, increased gains are expected.
\end{abstract}

Keywords: Interdisciplinarity; Logic programming; Elementary school II.

Data recebimento: $17 / 09 / 2020$

Data de aceite: 06/05/2021
* Professor do Instituto Federal Catarinense (IFC), Videira - SC, Brasil. Aluno de Doutorado da Universidade Federal de Santa Catarina (UFSC), Florianópolis - SC, Brasil. E-mail: diego.krohl@ifc.edu.br

** Aluna de Mestrado da Universidade do Estado de Santa Catarina (UDESC), Florianópolis - SC, Brasil. E-mail: taynara.dutra27@gmail.com

*** Aluna de Graduação do Instituto Federal Catarinense (IFC), Videira - SC, Brasil. E-mail: camillapozerm@gmail.com 


\section{Introdução}

A informática, por si só, é uma ferramenta interdisciplinar que atua como instrumento para a resolução/otimização dos desafios advindos das mais diversas áreas. No ensino, a informática ocupa papel relevante na formação de nível técnico e superior, mas encontra dificuldades de se engajar nas propostas de formação básica (QUEIROZ; SANTOS; RODRIGUES, 2016, GARCIA; BROD; HINZ, 2018).

No que se refere ao processo educativo interdisciplinar, de acordo com a resolução $\mathrm{n}^{\circ}$ 7 , de 14 de dezembro de 2010, art. 24, inciso $2^{\circ}$, fica estabelecido:

Constituem exemplos de possibilidades de integração do currículo, entre outros, as
propostas curriculares ordenadas em torno de grandes eixos articuladores, projetos
interdisciplinares com base em temas geradores formulados a partir de questões da
comunidade e articulados aos componentes curriculares e às áreas de conhecimento,
currículos em rede, propostas ordenadas em torno de conceitos-chave ou conceitos
nucleares que permitam trabalhar as questões cognitivas e as questões culturais numa
perspectiva transversal, e projetos de trabalho com diversas acepções (BRASIL, 2010).

Apesar desse enfoque, é incomum encontrar propostas abarcando essas premissas, sobretudo utilizando a informática como ferramenta integradora interdisciplinar. Aliás, esse é um dos grandes desafios deste século para a educação que, devido às novas demandas da sociedade, necessita aliar as tecnologias digitais ao contexto escolar, por meio da adequação da produção e socialização do conhecimento de maneira criativa e colaborativa (ARAÚJO; SOUZA; SILVA, 2014).

Os recursos tecnológicos empregados em sala de aula devem ser considerados como uma fonte de novas perspectivas de ensino-aprendizado, oferecendo ao aluno, por meio da interdisciplinaridade, uma forma de aliar as transformações que as tecnologias geraram na sociedade com o âmbito escolar (DIAS; CAVALCANTI, 2016). No que se refere ao conceito de interdisciplinaridade, muita discussão ocorreu ao longo do processo de evolução histórica do termo, entretanto um dos mais aceitos é o descrito por Japiassu (1976).

\footnotetext{
A interdisciplinaridade se define e se elabora por uma crítica das fronteiras das disciplinas, de sua compartimentação, proporcionando uma grande esperança de renovação e de mudança no domínio da metodologia das ciências humanas. Poderíamos dizer que o objetivo geral a ser alcançado não é outro senão o de descobrir, nas ciências humanas, as leis estruturais de sua constituição e de seu funcionamento (JAPIASSU, 1976, p. 54 e 55).
}

Uma das possibilidades da prática da interdisciplinaridade, que se dá por meio das interrelações entre os saberes, é o emprego da programação de computadores aliado aos conteúdos do ensino básico, metodologia esta que vem sendo defendida por inúmeros autores (QUEIROZ; SANTOS; RODRIGUES, 2016, GARCIA; BROD; HINZ, 2018). Isso é possível, pois o aprendizado da lógica de programação acarreta em diversos benefícios para os discentes, 
tanto no ambiente escolar quanto na vida pessoal, por meio do desenvolvimento do raciocínio metódico e pragmático. Além disso, como cita Nicolete et al. (2016), mesmo focando em uma área de conhecimento, muitas outras são afetadas, oferecendo ao aluno uma visão mais ampla sobre o contexto social, cultural e tecnológico.

Para oportunizar estes ganhos aos jovens da rede municipal de uma cidade situada no meio oeste de Santa Catarina, um projeto de extensão está sendo desenvolvido em três escolas. Por meio desse, crianças estão tendo a oportunidade de aprender a criar programas de computadores, desenvolver um melhor raciocínio e ainda obter conhecimento sobre os conteúdos regulares mediante uma nova abordagem de estudos.

O objetivo do presente trabalho é avaliar a viabilidade e as possibilidades existentes de práticas interdisciplinares aplicadas ao ensino de lógica de programação, conjuntamente às disciplinas de matemática, química e física. Destinado aos alunos do ensino fundamental II das três escolas, o projeto é fundamentado em abordagens descritas na literatura e nos resultados de um questionário aplicado aos docentes das disciplinas citadas, com vistas na consolidação e disseminação das alternativas mais promissoras (QUEIROZ; SANTOS; RODRIGUES, 2016).

\section{Metodologia}

Os procedimentos adotados para a realização do referido projeto envolveram duas principais atividades, divididas em seções.

Os aspectos inerentes à organização da proposta em si, bem como sua condução e as possibilidades de trabalhos interdisciplinares, que se apresentaram como uma das grandes ferramentas para execução das atividades, são fundamentados e apresentados na seção de aplicação do projeto. Com o seu aprimoramento, foi realizada a aplicação de um questionário aos docentes do ensino regular dos estudantes, permitindo um levantamento mais aprofundado, com o desígnio de efetivar a proposta interdisciplinar e proporcionar um aprendizado significativo aos estudantes. Esse processo é apresentado na seção do questionário docente.

Com base nas atividades realizadas, o estudo apresentado neste artigo é caracterizado como misto, com avaliações quantitativas perante as questões que são possíveis valorar, mas também qualitativa, pela análise de aspectos subjetivos da compreensão dos professores frente suas feições sobre o trabalho interdisciplinar. Esse tipo de trabalho está alinhado com a complexidade de problemas contemporâneos, que apresentam inúmeras faces, principalmente quando indicam reflexões sobre processos de ensino-aprendizagem (MERTENS, et al., 2016).

\section{Aplicação do projeto}

O presente trabalho descreve atividades executadas em um projeto de extensão, realizado em parceria entre três escolas públicas participantes e o Instituto Federal Catarinense 
(IFC), localizado na mesma cidade. No projeto, foram oportunizadas aulas de lógica de programação ministradas por docentes e graduandos do bacharelado em ciência da computação da instituição proponente, partindo de pressupostos da equipe e de autores como Queiroz; Santos; Rodrigues (2016).

As aulas foram realizadas no contraturno do ensino regular, nos próprios laboratórios de informática das escolas, que contam com uma infraestrutura limitada e pouco utilizada cotidianamente. Os computadores necessitaram de uma manutenção prévia, envolvendo limpeza, troca de componentes e atualização de softwares, para que então pudessem receber as ferramentas necessárias para a efetivação das aulas. Esses problemas encontrados são corroborados por Nazaré; Ribeiro; Frota (2016) que relatam que muitas vezes esses fatores dificultam a inserção de propostas para uso de tecnologias nas escolas.

O processo de seleção dos estudantes que participaram do projeto se deu por meio de divulgação nas salas de aula, sendo necessária prévia autorização dos responsáveis para que pudessem comparecer à instituição de ensino fora do seu período de aula regular. Esse processo contou diretamente com o auxílio das coordenações pedagógicas/direções das escolas. Os alunos se inscreveram para o projeto de maneira voluntária, de acordo com seu interesse e disponibilidade de horário.

Foi realizado, previamente, o planejamento das aulas, com avaliação das ferramentas e práticas a serem adotadas no transcorrer das atividades. Com o propósito de facilitar a escrita dos códigos e oferecer uma interface e linguagem de programação com a mesma lógica e com proximidade às estruturas das linguagens utilizadas no mercado, o software utilizado para o desenvolvimento da programação foi o VisuAlg. Por ser em português e possuir uma sintaxe simples, a ferramenta é ideal para iniciantes, principalmente jovens que não detém conhecimentos nessa área. Além disso, proporciona o contato dos discentes com um ambiente de desenvolvimento muito semelhante aos utilizados profissionalmente, porém mais simples e intuitivo (DANTAS et al., 2012).

A base das aulas de lógica de programação aplicadas emprega a metodologia de resolução de problemas. Conforme descrito por Coelho (2014), essa técnica "desenvolve habilidades utilizando várias estratégias, fazendo com que o aluno se aprimore cognitivamente $\mathrm{e}$ se aproprie de métodos e técnicas para resolver problemas". As questões aplicadas em sala são pertinentes à vida acadêmica e cotidiana dos discentes e foram propostas visando à discussão das mais eficazes e rápidas soluções, além de possibilitar ao estudante um panorama mais real e aplicável da programação (GARCIA; BROD; HINZ, 2018).

A interdisciplinaridade é um ponto forte no projeto, sobretudo com os conteúdos de matemática, física e química. Isso se dá pela criação, pelos estudantes, dos códigos para resolução de tarefas que envolvem, principalmente, questões relacionadas aos assuntos do ensino regular (QUEIROZ; SANTOS; RODRIGUES, 2016). Tais questões, aplicadas conforme estudadas em suas respectivas disciplinas, oportunizam ao aluno um novo olhar sobre o mesmo tema, o que facilita a compreensão da programação, visto que conseguem visualizar sua aplicação e também colabora para uma melhor apropriação do conteúdo. 
De acordo com a disponibilidade dos professores, foram realizadas conversas visando ao planejamento de ações correlacionadas entre os assuntos das disciplinas e as atividades do projeto. Um exemplo da prática da inter-relação com os saberes dos discentes foi a criação de um algoritmo para resolução da fórmula de Bhaskara, que pode ser verificado na figura 1.

Figura 1 - Algoritmo para resolução da fórmula de Bhaskara

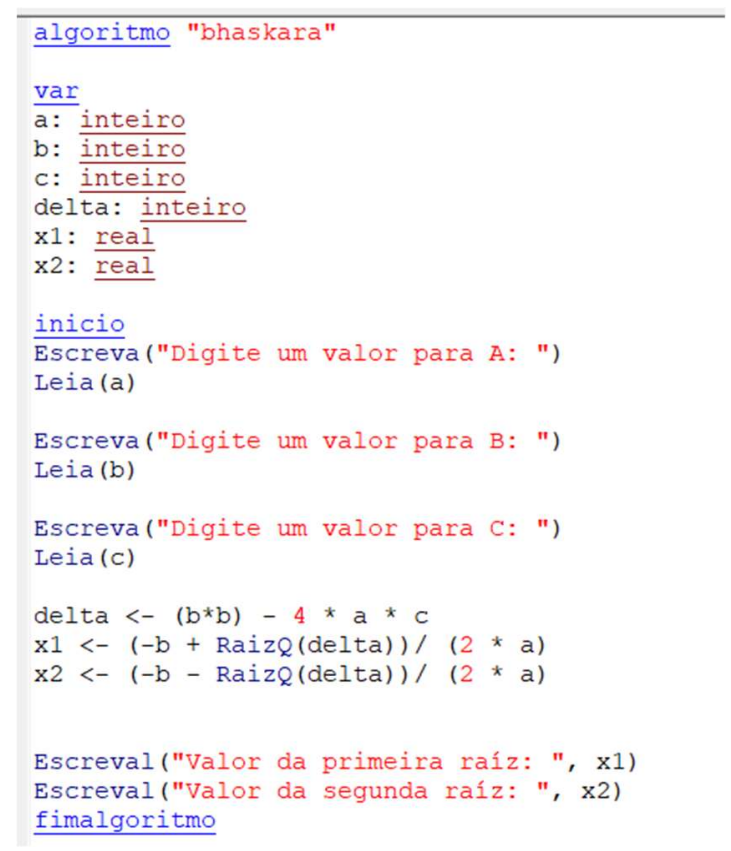

Fonte: Os autores

Além da fórmula, é possível observar na figura 1 a estrutura básica da linguagem desenvolvida na ferramenta Visualg, em que se apresenta a declaração das variáveis, os comandos de escrita e leitura de valores, cálculos realizados, bem como a impressão dos resultados calculados.

Somado a isso, alguns exercícios tinham o propósito de aliar-se à vivência cotidiana dos estudantes. Assim sendo, outro exemplo de programa desenvolvido foi a implementação de um simulador de caixa eletrônico, que replica ações simples, tais como: depósito, saque, transferência de valores e os cálculos necessários para tal. A simulação de um caixa de mercado e a passagem de produtos que seriam comprados também foi feita. Esses exercícios tinham como objetivo despertar novas perspectivas nos alunos para que os mesmos percebessem o quão a matemática e também a programação estão relacionadas a tarefas simples do dia a dia. O modelo de aplicação, bem como a metodologia utilizada, seguem premissas descritas por Nazaré; Ribeiro; Frota (2016), que descrevem uma aplicação similar à proposta descrita no presente trabalho, porém o enfoque fica limitado aos softwares.

O projeto iniciou em uma escola da cidade, mas com os bons resultados obtidos, posteriormente, foi aplicado em mais duas. O propósito foi expandir para mais escolas e oportunizar 
aos alunos a chance de conhecer a lógica da programação e perceber sua utilidade no âmbito escolar, social e, futuramente, profissional. Dessa forma, a cada semestre, buscam-se novas parcerias com outras escolas do município, a fim de disponibilizar essa oportunidade para a maior quantidade de estudantes.

Como um meio de avaliação do projeto e também da evolução dos estudantes, foi aplicado um questionário diagnóstico no primeiro dia de execução das atividades, contendo quinze questões lógicas, subdivididas em fáceis, medianas e difíceis. No último dia do projeto, foi aplicado um questionário nos mesmos moldes do primeiro. As questões dispostas nesse questionário objetivavam permitir uma análise quantitativa dos dados, fornecendo subsídios para um estudo no potencial de resolução de problemas e uma comparação em relação ao progresso do raciocínio lógico e sistêmico dos alunos. Além dessas questões lógicas, foram realizadas perguntas de cunho pessoal sobre as percepções acerca do projeto. Esses dados são apresentados ao final do tópico de resultados e discussão.

\section{Questionário docente}

A troca de informações entre os professores é aspecto fundamental para atividades interdisciplinares. Assim, é possível identificar as potencialidades a serem trabalhadas (NAZARÉ; RIBEIRO; FROTA, 2016). Consequentemente, a proposta do projeto de ensino de lógica de programação é também possibilitar aos estudantes um momento extra para revisar conteúdos aprendidos em outras disciplinas, de modo que se apresente um novo meio de resolução para problemas trabalhados cotidianamente no ensino regular. Dessa forma, o uso da tecnologia apresenta-lhes um novo significado, fazendo com que os recursos tecnológicos deixem de ser apenas um meio de entretenimento, transformando os alunos em produtores de soluções computacionais (FERREIRA et al. 2015).

Tendo vistas a uma maior aproximação entre os responsáveis pela execução do projeto e os professores do ensino básico das disciplinas da área de ciências exatas e da natureza, foi desenvolvido um questionário para identificar, primeiramente, o perfil dos docentes desse grupo, sua experiência com ensino e sobretudo o limiar do trabalho interdisciplinar. Depois, foi possível traçar um melhor planejamento na forma de abordar os docentes e propor atividades que possam integrar os conteúdos trabalhados durante as atividades de programação (NAZARÉ; RIBEIRO; FROTA, 2016). Os professores das três escolas participantes do projeto foram convidados a responder o questionário de maneira voluntária, anônima e sigilosa. Isso possibilitou que realizassem suas considerações frente às perguntas e refletissem de forma sincera. O principal intuito do questionário aplicado aos docentes era identificar as possibilidades de interdisciplinaridade, caracterizando-se como uma pesquisa qualitativa, a qual lida com as interpretações das realidades e a subjetividade (BAUER; GASKELL, 2017). O planejamento e a elaboração do questionário aplicados aos docentes fundamentou-se nas orientações dispostas por Field (2003). Em relação aos questionamentos, em maior número, empregou-se questões abertas de cunho qualitativo para propiciar a expressão textual de opiniões e julgamentos parti- 
culares (COELHO; SOUZA; ALBUQUERQUE, 2019). Apenas em uma única questão não poderia haver considerações pessoais, a que indagava em relação ao tempo de docência no ensino fundamental II. A forma de repasse do questionário foi impressa, assim foi possível que, no período de uma semana, respondessem e efetuassem a devolutiva (FERREIRA et al., 2015).

No total, foram colhidas catorze respostas advindas dos docentes das três escolas. O método de análise de dados, partindo do pressuposto da pesquisa mista, buscou agrupar quantitativamente em conjuntos as respostas que eram condizentes, porém elas foram individualmente verificadas na busca por oportunidades e soluções descritas pelos docentes (MERTENS, et al., 2016).

Ressalta-se que o projeto desenvolvido é de extensão, por conseguinte não houve a necessidade da submissão ao comitê de ética da instituição promotora. No entanto, medidas foram adotadas para evitar riscos, tanto aos professores quanto aos estudantes respondentes dos questionários, conforme relatado. Todos os dados coletados foram de anônimos e nenhuma das indagações requeria informações particulares com o intuito de garantir que as respostas não pudessem ser vinculadas. Assegurou-se a confidencialidade e a privacidade, bem como a não utilização dos dados em prejuízo das pessoas e instituições envolvidas.

\section{Resultados e discussão}

A partir da obtenção dos resultados dos questionários e avaliação dos mesmos, foi possível enquadrar os professores de acordo com seu tempo de experiência na docência do ensino fundamental II. Esses dados são apresentados na figura 2.

Figura 2 - Tempo de docência no ensino fundamental II

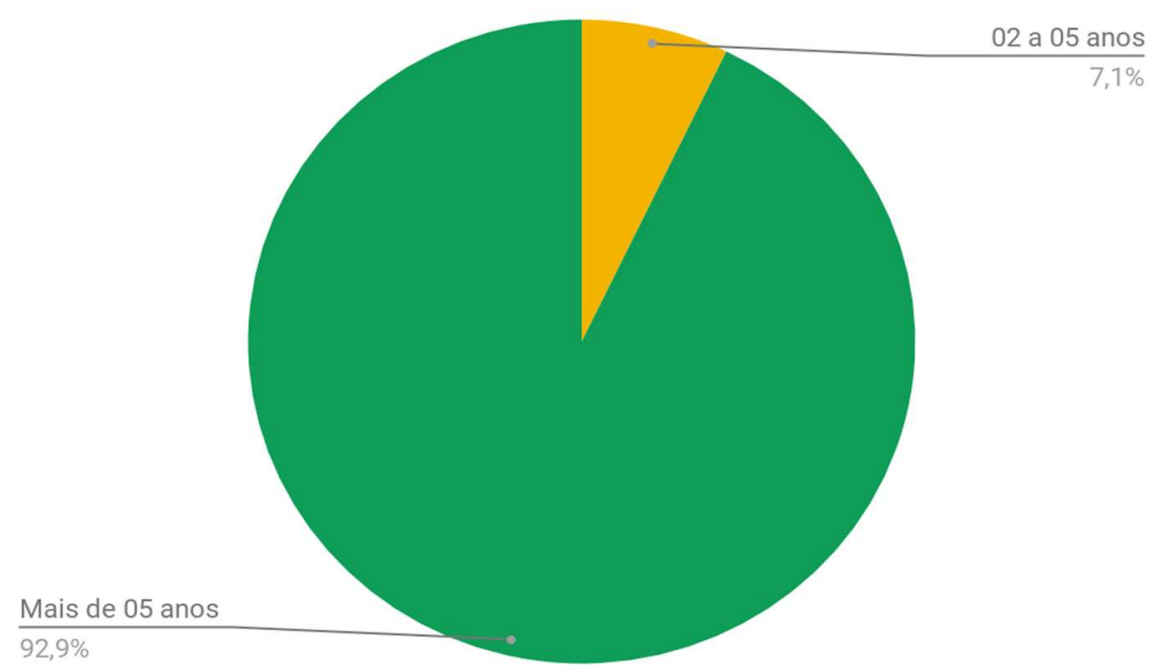

Fonte: Os autores 
A partir desses dados, observa-se que a grande maioria dos docentes $(92,9 \%)$ atua no ensino fundamental II há mais de cinco anos; 7,1\% atua entre dois e cinco anos e as opções entre um e dois anos e menos de um ano não contemplaram nenhum professor, o que demonstra uma boa experiência em trabalhos com esse perfil de estudantes. Também é possível constatar que as respostas expressas nos questionários apresentam um retrato do que vem acontecendo nos últimos anos de disciplinas das ciências exatas e da natureza, da área de exatas, nesta cidade do meio oeste catarinense.

Quando a pergunta foi "Para você, o que é interdisciplinaridade?", as repostas foram variadas, evidenciando que todos os docentes emitiram a sua visão individual sobre o tema. Parte das respostas se encontram no quadro 1.

Quadro 1 - Trechos das respostas dos docentes sobre o conceito pessoal de interdisciplinaridade

Professor C - [...] É quando dois ou mais professores de disciplinas diferentes planejam juntos, relacionando seus conteúdos dando base para um ensino mais interessante, onde uma matéria auxilia a outra. Para isso ambos os professores devem estar comprometidos com o projeto.

Professor D - [...] É quando as disciplinas atuam junto (coletivamente) em função de um objetivo. Diferente de multidisciplinaridade, onde um tema norteia várias disciplinas que não se complementam no planejamento.

Professor F - [...] Trabalho em grupo com o fim dos limites entre as disciplinas, maior interação entre professores e alunos, com metodologias diferentes em um mesmo conteúdo.

Professor I - [...] É quando duas ou mais disciplinas relacionam seus conteúdos para um objetivo em comum. Na verdade é um diálogo entre duas ou mais disciplinas proporcionando/buscando a melhor compreensão de áreas afins ou não.

Fonte: Dados da pesquisa

Destaca-se que as respostas apresentadas convergem, no geral, para a definição conceitual de interdisciplinaridade, o que demonstra alto nível de compreensão sobre o tema. Também é possível ter a dimensão de que é factível realizar a proposta dentro do contexto do projeto aos docentes, aprimorando o trabalho desenvolvido, beneficiando assim os estudantes com um processo de aprendizagem significativo entre as disciplinas.

Quando o questionamento foi se o professor já havia trabalhado de maneira interdisciplinar, todos responderam afirmativamente, o que dá a dimensão de que propostas interdisciplinares são realizadas dentro das escolas e os docentes já têm vivência com esse tipo de atividade.

Na pergunta "Você sente dificuldade em trabalhar interdisciplinarmente?", a resposta dos docentes foi "não". Dessa forma, um cenário propício para esse tipo de ação foi constatado, deixando as portas abertas para o planejamento de ações conjuntas com esses professores. 
Sobre a efetividade do auxílio das práticas interdisciplinares, na pergunta "Acredita que os trabalhos interdisciplinares realmente irão ajudar alunos e professores?", algumas respostas se destacaram e são apresentadas no quadro 2 .

Quadro 2 - Trechos das respostas dos docentes sobre as benesses das práticas interdisciplinares

Professor A - [...] Acredito, pois os alunos perceberão que os conteúdos estão todos relacionados, facilitando a aprendizagem.

Professor C - [...] Com certeza, pois o trabalho interdisciplinar garante uma maior interação entre os alunos e professores, sem falar na troca de experiências, melhora a socialização e a vivência em grupo.

Professor K - [...] Sim. A relação entre as disciplinas é muito importante, pois, estimula a pesquisa, curiosidade e a vontade de aprender e entender o tema estudado.

Professor M - [...] Sim. Todos ganham com a interdisciplinaridade. Os alunos porque aprendem a trabalhar em grupo. Os professores porque se veem compelidos pelos próprios alunos a ampliar os conhecimentos de outras artes. Tendo também menos problemas de disciplina.

Fonte: Dados da pesquisa

A base das respostas colhidas no quadro 2 demonstra uma perspectiva positiva quanto à efetividade do auxílio das práticas junto aos estudantes. Tendo como base que é perceptível aos docentes a melhor interação entre os conteúdos e a assimilação pelos estudantes, propostas de trabalhos interdisciplinares podem fazer parte do processo educativo. Destaca-se ainda a resposta do professor $\mathrm{C}$, que aponta a perspectiva social que esse tipo de ação proporciona, refletindo tanto na atividade docente quanto discente.

Esse viés de rompimento das barreiras disciplinares tange para a perspectiva defendida por Pombo (2005, p. 12), "situação que reclama, qual seu contraponto, um público cada vez mais informado, capaz de se interessar, de se inquietar, de mesmo exigir, criticar, protestar, resistir". Isso demonstra que o caminho é a busca pela significância do aprendizado como um todo. Não basta apenas a especialização em uma área, mas sim uma compreensão de como os conhecimentos tangem entre si.

Quando o questionamento foi "Acredita que atividades que utilizam tecnologias em conjunto com o ensino regular trazem benefícios aos estudantes?", destacaram-se os seguintes trechos das respostas dos professores, apresentados no quadro 3. 
Quadro 3 - Trechos das respostas dos docentes sobre o uso de tecnologias no ensino regular

Professor C - [...] Sim, porque as tecnologias estão cada vez mais presentes no nosso dia a dia, é uma ferramenta que torna as aulas mais atraentes e inovadoras, melhora a integração entre aluno e professor, desperta a curiosidade do aluno estimulando-o a aprender e a ensinar também.

Professor D - [...] Sim, a tecnologia é parte presente no cotidiano de todos na contemporaneidade e na educação vem como importante ferramenta complementar.

Professor E - [...] Sim, desde que usadas com sabedoria é um excelente subsídio do processo de ensinoaprendizagem.

Professor K - [...] Sim. As vantagens são evidentes tanto para professores quanto para alunos, desde, que seja de forma planejada e corretamente, pois abre uma enorme porta de possibilidades de conhecimentos.

Fonte: Dados da pesquisa

Esse retorno positivo dos docentes corrobora com Santos et al. (2017), pois avaliza que a práxis docente deve estar em constante mudança, alinhada com as tendências e perspectivas tecnológicas presentes no cotidiano da geração de nativos digitais. Isso permitirá um salto de qualidade no ensino tradicional, pois maximizará o ensino, proporcionará ferramentas diversificadas aos docentes e possibilidades de inclusão digital aos estudantes.

A última pergunta realizada foi a seguinte: "Acredita que atividades que promovam o uso do raciocínio lógico pelos alunos influenciam na sua formação?”. A pergunta teve o objetivo de avaliar a percepção, por parte dos docentes, quanto à importância de atividades envolvendo o raciocínio lógico dos estudantes e se na opinião dos mesmos ocorriam reflexos dessa prática no cotidiano da sala de aula. Como respostas, destacaram-se as apresentadas no quadro 4.

Quadro 4 - Trechos das respostas dos docentes sobre práticas envolvendo raciocínio lógico

Professor A - [...] Acredito que sim, pois são maneiras de auxiliar na formação educacional, desenvolvendo um senso criativo na interpretação de certas situações no seu cotidiano.

Professor C - [...] Sim, pois o desenvolvimento do raciocínio lógico nos alunos faz com que eles passem a pensar de forma mais crítica, argumentativa e correta sobre os conteúdos de todas as disciplinas. Esse aprendizado torna-os mais capazes de organizar e concretizar as situações vivenciadas no cotidiano escolar e na própria vida, no seu dia a dia.

Professor L - [...] Com toda certeza! Ainda mais hoje, no qual dependemos cada vez mais de calculadoras, computadores e aparelhos que pensam por nós.

Professor M - [...] Sim, pois a utilização do raciocínio lógico gera pessoas críticas, com senso argumentativo, alunos capazes de criar, interpretar, responder e explicar situações problema envolvendo matemática.

Fonte: Dados da pesquisa 
Com os argumentos auferidos no quadro 4, destaca-se que os professores concordam que atividades que estimulam o raciocínio lógico dos estudantes são fundamentais, visto que auxiliam não só nas atividades escolares, mas também em aspectos cotidianos. Esse é justamente um dos objetivos do projeto de ensino de lógica de programação executado, desenvolver capacidades nos alunos que transcendam as perspectivas escolares, ampliando suas aptidões como um todo.

Com o intuito de avaliar as percepções e desempenho dos alunos na primeira turma que participou do projeto, eles também foram avaliados com questionários, assim como descrito na metodologia. No questionário inicial, o qual avaliava a capacidade de resolução de questões lógicas, a taxa de acertos alcançou $50 \%$ em média, sendo $72 \%$ das questões fáceis, $48 \%$ das médias e $31 \%$ das difíceis. No final, o índice de acertos total aumentou para $60 \%$, pois as questões obtiveram $70 \%, 58 \%$ e $54 \%$, respectivamente. Portanto, o incremento comparativo entre as duas aplicações foi de $10 \%$ de acerto.

Com esses resultados, pode-se afirmar que houve uma melhora perceptível na capacidade dos alunos responderem as questões assertivamente no período de realização do projeto. A evolução também se deu ao longo da realização das aulas. Os alunos propunham alternativas para a resolução dos casos trabalhados, demonstrando seu interesse em participar das aulas e evoluir suas capacidades.

Somado às questões lógicas, no questionário final foram feitas perguntas relacionadas à percepção dos alunos sobre os benefícios do projeto e atividades que mais gostaram. Todos perceberam melhoras quanto ao raciocínio lógico. A criação de programas e a interdisciplinaridade foram as mais citadas como metodologias que possibilitaram um melhor entendimento dos trabalhos. Assim, destaca-se a relevância percebida pelos próprios discentes no trabalho conjunto dos temas, favorecendo sua compreensão frente às possibilidades correlacionais entre os assuntos do ensino regular e do aprendizado de lógica de programação.

\section{Considerações finais}

Este trabalho teve como objetivo buscar e explanar as vantagens da interdisciplinaridade entre o ensino básico e a programação, mostrando formas de realizar esse processo, bem como publicar resultados já obtidos em um projeto de extensão realizado.

As aulas de programação visavam, primeiramente, ao aprimoramento do raciocínio lógico dos estudantes por meio da resolução de problemas cotidianos e interdisciplinares. Além disso, mostrar que a informática pode auxiliar o aprendizado, tanto como facilitar o processo de ensino dos professores do ensino regular. 
O questionário docente aplicado forneceu subsídios para uma melhor compreensão do cenário escolar onde o projeto de ensino de lógica de programação é desenvolvido. Foram colhidas informações importantes, demonstrando o alto nível de experiência dos professores, tanto no ensino como em trabalhos interdisciplinares. As respostas apresentaram também suas feições sobre esses trabalhos que demonstraram grande interesse em realizar. No viés da importância da tecnologia e do exercício da lógica nas atividades, houve unanimidade entre as respostas, com vistas às possibilidades contemporâneas da articulação entre esses temas e o ensino.

$\mathrm{Na}$ execução do projeto, quando houve a junção da lógica de programação com os conteúdos aprendidos em sala, o entendimento adquirido pelos estudantes não ficou restrito a esses dois panoramas. Os resultados alinharam-se com os descritos por Nicolete et al. (2016), em que diversas áreas de conhecimento foram atingidas como decorrência da aplicação da interdisciplinaridade. Aprendendo a lidar com problemas matemáticos por intermédio da programação, é possível aplicar a mesma lógica para problemas cotidianos e sociais, não restringindo apenas ao âmbito escolar.

A proposta aplicada até o momento foi exitosa, tendo como base as melhorias percebidas nos questionários aplicados aos alunos que participaram do projeto em sua primeira execução. Uma maior rapidez na resolução dos problemas, assim como uma análise do melhor caminho para seu desenlace foram comprovadas pelos resultados promissores obtidos. É inegável que a interdisciplinaridade auxiliou na obtenção de tais resultados, visto que ofereceu aos alunos um panorama mais amplo, tanto da informática como das disciplinas da base regular. Também há de se destacar que não se designa essa evolução apenas ao projeto executado, visto que os alunos estão em um processo educativo e de desenvolvimento constante, mas cabe ressaltar que é uma proposta que contribui de maneira efetiva no aprendizado.

Destaca-se que com a continuação do projeto, novos resultados serão obtidos, porém com os estudos realizados dentro dessa proposta, a metodologia está constantemente sendo lapidada, buscando a operacionalização das aulas e da interdisciplinaridade que, efetivamente, se apresenta como um alicerce para a continuidade e melhoria dos resultados.

\section{Agradecimentos}

Ao Instituto Federal Catarinense (IFC) pelo apoio para a realização de projetos de extensão e às escolas parceiras pela confiança no trabalho realizado.

Ao Programa de Bolsas de Monitoria de Pós-Graduação (PROMOP) da Universidade do Estado de Santa Catarina (UDESC). 


\section{Referências}

ARAÚJO, A. P. F. ; SOUZA, P. R. ; SILVA, J. A. M. Uso do Scratch no processo de aprendizagem em sala de aula: relato de experiências de alunos do mestrado profissional de ensino tecnológico/IFAM. Revista brasileira de educação profissional e tecnológica, v. 1, n. 7, p. 125-136, 2014.

BAUER, M. W.; GASKELL, G. Pesquisa qualitativa com texto, imagem e som: um manual prático. Editora Vozes Limitada, 2017.

BRASIL. Ministério da Educação/Conselho Nacional de Educação/Câmara de Educação Básica. RESOLUÇÃO N. 7, de 14 de DEZEMBRO DE 2010. Fixa as Diretrizes Curriculares Nacionais para a Educação Infantil. Brasília, 2010.

COELHO, M. S. L. Os Desafios da Escola Pública Paranaense na perspectiva do professor PDE. Cadernos PDE. v. 2, 2014.

COELHO, J. A. P. M.; SOUZA, G. H. S.; ALBUQUERQUE, J. Desenvolvimento de questionários e aplicação na pesquisa em Informática na Educação. Metodologia de Pesquisa em Informática na Educação: Abordagem Quantitativa de Pesquisa. Porto Alegre: SBC. Série Metodologia de Pesquisa em Informática na Educação, v. 2, 2019.

DANTAS, S. S.; MORAIS, L. A. M.; LOPES FILHO, J. G.; RODRIGUES, R. S.; COSTA, R. A. Avaliação de um software educacional de apoio à aprendizagem de programação: Visualg. In: VII CONNEPI-Congresso Norte Nordeste de Pesquisa e Inovação, 2012.

DIAS, G. A.; CAVALCANTI, R. A. As tecnologias da informação e suas implicações para a educação escolar: uma conexão em sala de aula. Revista de pesquisa interdisciplinar. Cajazeiras, v.1, n. especial, p. 160-167, 2016.

FERREIRA, A. C. C.; MELHOR, A.; BARRETO, J. S.; PAIVA, L. F.; MATOS, E. Experiência Prática Interdisciplinar do Raciocínio Computacional em Atividades de Computação Desplugada na Educação Básica. In: Anais do XXI Workshop de Informática na Escola, p. 256. 2015.

FIELD, A. Designing a questionnaire. 2003. Disponível em:

$<\mathrm{http}: / / \mathrm{www}$.discoveringstatistics.com/docs/designing_questionnaires.pdf $>$. Acesso em: dez, 2020.

GARCIA, M. P.; BROD, F. A. T.; HINZ, V. T. SCRATCH como Proposta para significar as aprendizagens de Algoritmos no Curso Técnico em Desenvolvimento de Sistemas.

Revista Educar Mais. v. 2, n. 01, 2018. 
JAPIASSU, H. 1976. Interdisciplinaridade e Patologia do Saber. Rio de Janeiro: Editora Imago.

MERTENS, D. M.; BAZELEY, P.; BOWLEG, L.; FIELDING, N.; MAXWELL, J.; MOLINA-AZORIN, J. F.; NIGLAS, K.. Expanding thinking through a kaleidoscopic look into the future: implications of the mixed methods international research association's task force report on the future of mixed methods. Journal of Mixed Methods Research, v. 10, n. 3, p. 221-227, 2016.

NAZARÉ, W. B.; RIBEIRO, L. M. B.; FROTA, V. B. Um modelo interdisciplinar com ênfase na inclusão da informática na formação básica e média. In: Nuevas Ideas en Informática Educativa. Santiago de Chile. v. 12, p. 579-584, 2016.

NICOLETE, P. C.; BILESSIMO, S. M. S.; FREIRE, P. S.; SILVA, J. B.; CRISTIANO, M. A. S. Integração tecnológica na educação básica pública brasileira: Uma análise sobre a evolução temporal e a interdisciplinaridade do tema. RIAEE - Revista Ibero-Americana de Estudos em Educação, v. 11, n. 4, p. 2064-2086, 2016.

POMBO, O. Interdisciplinaridade e integração dos saberes. Liinc em Revista, v. 1, n. 1, p. 3-15, 2005.

QUEIROZ, P. S.; SANTOS, H. R. M.; RODRIGUES, A. N. Relato de Experiência no PIBID: Projeto interdisciplinar envolvendo Licenciandos em Computação e Pedagogia no Ensino Fundamental. Anais do Workshop de Informática na Escola. v. 22, n. 1, 2016.

SANTOS, A. O. S.; SOUZA, A. E. S. B.; AREIAS, G. B.; ASSUNÇÃO, J. P. P.; NOBRE, I. A. M.; NUNES, V. B. Tecnologias digitais no ensino de física: uso de celular na abordagem de conteúdos programáticos de velocidade. Revista Eletrônica Debates em Educação Científica e Tecnológica, Vitória - Espírito Santo, v. 7, n. 3, p 208-228, Dezembro de 2017. 